\title{
National Research and International Competitiveness - An Antinomy?
}

\section{DOI 10.1007/s12599-010-0115-7}

\section{The Authors \\ Prof. Dr. Peter Loos ( $₫)$ \\ IWi at DFKI \\ Saarland University \\ 66123 Saarbrücken \\ Germany \\ loos@iwi.uni-sb.de \\ Wolfgang König \\ Hubert Österle \\ Marco De Marco \\ Joan A. Pastor \\ Frantz Rowe \\ Published online: 2010-07-14}

This article is also available in German in print and via http://www. wirtschaftsinformatik.de: Loos $P$, König W, Österle H, De Marco M, Pastor JA, Rowe F (2010) Nationale Forschung und internationale Wettbewerbsfähigkeit - ein Widerspruch? WIRTSCHAFTSINFORMATIK. doi: 10. 1007/s11576-010-0231-5.

(c) Gabler Verlag 2010

\section{Introduction}

Research results should be shared internationally and have to face international competition. This requires their publication in the lingua franca of business and science, the English language. This especially applies to the so-called top-level research. The individual scientific disciplines have arrived at different stages in the transformation process of internationalization. Many of the findings of German-language research in Business and Information Systems Engineering (BISE) are now being published in English. Since 2009, also the journal WIRTSCHAFTSINFORMATIK has been published in the English language (Buhl 2009).

Even if the international orientation may be indisputable in principle, the scientific community of BISE researchers expresses concerns about possible side effects. One facet of these side effects can be seen, for example, in the current debate about a contribution in the section "State of the art" on measuring the success of information systems (Buhl et al. 2010): How do you deal with research findings which were not published in Englishlanguage top journals, but are available in other publication media in the German language?

A major cause of this side effect is attributed to the fact that top-research and its measurement are judged primarily on the basis of publications in Anglo-Saxon, high-ranking journals. If researchers are judged primarily by the number of these publications, such as in appointment procedures, this means that internationalization also leads to the adoption of the Anglo-Saxon culture of research, often following a behavioral research approach, while in German-language BISE research so far the focus has been on design-oriented research (Österle et al. 2010). Moreover, the connection between scientists and their object of study, which for BISE are companies and organizations, may be lost - a problematic development for BISE as an applied science.

Therefore, this discussion deals with the question what importance should be given to publications in internationally renowned scientific journals and what role other forms of publication, such as monographs and edited volumes, may take. Furthermore, we should reflect on the question of the implications arising from the orientation towards AngloSaxon evaluation criteria. If the research approaches which do not meet these evaluation criteria lose in importance, such as design-research, does this mean a threat to pluralism in research, or is it a necessary adjustment process? These issues are not to be discussed from the perspective of German-speaking BISE researchers alone. Additionally, to gain insights into the situation of the scientific communities of our neighboring European countries may be useful. Therefore also participants from France, Italy, and Spain were invited to participate in this debate. The following authors accepted my invitation to this discussion (in alphabetical order):

- Prof. Dr. Marco De Marco, Facoltà di Economia, Università cattolica del Sacro Cuore, Milano, Italy

- Prof. Dr. Wolfgang König, Chair of Economics, esp. Information Systems, University of Frankfurt, Germany

- Prof. Dr. Hubert Österle, Institute of Information Systems, University of St. Gallen, Switzerland

- Prof. Dr. Joan A. Pastor, Information Systems and Software Engineering Research Group, UPC Technical University of Catalonia, Barcelona, Spain

- Prof. Dr. Frantz Rowe, Institut d'Economie et Management de Nantes, France

König affirms the importance of international competition. National allowances in terms of research strategy and agenda tend to be at the expense of research quality. The globally emerging research issues show a higher level of performance as the number of scientists is increasing. The German-speaking "designoriented" research must also face the international laws of research competition. In his recommendation for young researcher he highlights the publications in top international journals. He also pleads for cumulative doctoral theses as their evaluation is based closely on international rankings. In König's view, international top publications are a scientist's primary obligation, whereas other tasks, such as German-language publications, book publications, and the knowledge transfer, come second.

Österle also emphasizes the need for international competition which Germanlanguage BISE has to face. However, as a result of the outstanding importance of the English language, particularly Anglo-Saxon criteria of competition dominate the international and increasingly also the national competition. Therefore, Österle mentions the risk that the behavioral research approach, which prevails in Anglo-Saxon research, may displace other research approaches. Moreover, in his eyes the importance of book publications and individual research topics seems to be disappearing. 
The question of the benefits of research to society is pushed into the background. Therefore, he is critical of some emerging developments, such as the cumulative doctoral theses, and hopes that particularly established researchers do not align their publication strategies with one-dimensional criteria alone.

De Marco highlights the different approaches and methods in international BISE with its many facets, ranging from engineering to psychology. He leads this back to the social and economic context of research, among others. For example, many research contributions in Italy deal with SME as these dominate the Italian economy. Apart from publications in international journals, he also considers books and national journals as important publication media. Therefore, young scientists should pursue a balanced mix of publications. De Marco describes changes in the Italian university system, leading to the adoption of Anglo-Saxon standards and evaluation criteria. He mentions the implied risks and illustrates this by way of the biological evolution. He explains that the methods pluralism of the scientific discipline suffers from a uniformly narrow and rigid selection system. Therefore, he argues in favor of the application of differentiated evaluation systems in order not to endanger the diversity in research.

Pastor describes the prevailing research approach of BISE in Spain as designoriented, whereas in Spain no homogeneous scientific community as in Germany exists. In the public debate on research policy, the large gap between investment in universities and research institutions on the one hand and the lack of economically useful results in terms of products, patents, and spin offs on the other hand is criticized, which has implications on the current conditions of national research funding. For BISE, it appears that university research has hardly any relations to the local economy. In Pastor's view, the reason seems to be that so far there was a lack of incentives. The fact that most researchers publish in the English language and in international media sometimes leads to complaints regarding the fact that researchers are not interested in local issues. According to Pastor, an important point for a future successful research is an appropriate globalization, where research develops in the light of local issues and local cooperation, following global policies in a fair coopetition.
Rowe notes that English-language publications are also important from a French point of view, in particular for high-level contributions. He describes several steps that are necessary to change a high quality French publication into an English-language that can be placed in an international high-ranking journal. This transformation can lead to significant differences between the national and the international publication. Therefore, Rowe recommends that young scientists should start with national publications, whilst established scholars should apply a mixed strategy. Additionally, he recommends to cooperate with American coauthors for contributions in American, high-ranking journals or to publish in international high-ranking journals with a European background.

All contributions make clear that a strong international orientation of BISE research is necessary and desirable. This is true for both our scientific discipline as a whole and for individual researchers. However, some participants of this discussion highlight the risk that the dominance of the behavioral research approach in the journals at the top of the rankings leads to a one-sided orientation of global research, and thus results in an impoverishment of research approaches. If you would like to comment on this topic or another article of the journal Business \& Information Systems Engineering (BISE), please send your contribution (max. 2 DIN A4 pages) to the editor-in-chief, Prof. Hans Ulrich Buhl, University of Augsburg, HansUlrich.Buhl@wiwi.uni-augsburg.de.

\section{Prof. Dr. Peter Loos} IWi at DFKI

Saarland University Saarbrücken, Germany

\section{Top Publications in English as Obligation and German-Language Media as Option}

The issue formulated by the responsible editor of the section "BISE - Discussion" is as follows: "What publication strategy should young researchers pursue in the controversial field of Englishvs. German-language publications?" Furthermore, he added some detailed questions in this context which I will try to answer by first focusing on young academics who tend towards the research elite (and more research-oriented universities require such achievements): (a) Why are English-language - international - publications important? Internationally, a lot more researchers work on specific topics than nationally, resulting in a more intense competition for the best results which, in turn, usually leads to a faster contouring of research and a higher quality of its results. In comparison: During the World Athletics Championship (a selection of several billion people) the level of performance is higher than that of the German Athletics Championship (population: about eighty million people).

From a specifically Germanlanguage perspective it should be added that in the top international journals scholarly discourse on methods and results is much more intense than in German-speaking countries. For instance, one of our articles is currently subject to a review procedure in an international journal in the second round of review and comprises not less than 43 (!) pages of discourse between the authors and reviewers beyond the article itself (18 pages in length). And in case of an earlier, already accepted contribution the responsible editor of the international journal called us and we discussed the entire article word for word on the phone - in 150 minutes. There are distances between the 25 national and 25 international top researchers - these differences are continued by the observable efforts in this country to make national or local allowances for leading members (sometimes with the argument that the authors could better use the time they spend in intensive discussions with reviewers for other research tasks) - which tends to affect the quality of the contributions.

This means in conclusion: If you have conducted excellent research with interesting results, you should always aim at a publication in a top international journal (and, once this is achieved, one can and should follow further objectives in a second step - see comments at the end).

(b) Is there a scientific duty of care to consider foreign language-non-Englishpublications? This question I would like to answer with a reserved "yes". Top researchers should in principle keep their eyes and ears open for results beyond the contributions in top international journals. In the 
daily work, however, experience underlines that the amount of the top results published there is very low, so that the chance to discover them is very limited. This probability is further decreasing as an increase of globalization is now clearly observable in science as well - also the Spanish- and Chinese-language research colleagues (just to mention these two groups) are increasingly piling into English-language media with their top results.

(c) How can German-language contributions be considered in Englishlanguage publications? Only a very small percentage of international colleagues speak German to some extent. This means that the obvious way, which I would describe as "acting in the global community by means of decentralized selforganization", is virtually excluded for solving this issue. This leaves only one option which is that Germanspeaking authors - i.e., foremost those from our German-speaking community - within their Englishlanguage articles process the most important research results from the local area that are different from the general international view - different, since those findings that just subsequently confirm the international state of knowledge do not deeply enhance general knowledge (and given the common time constraints, one should only invest additional time and attention with regard to such an objective).

A completely different approach to answering the question was recently established by the journal WIRTSCHAFTSINFORMATIK: By means of a strong support from the German economy, German-language contributions are translated and published 1:1 into the English language - and thus, they are read internationally, and - hopefully - cited. Basically, it should be emphasized that WIRTSCHAFTSINFORMATIK, as a German-language journal until the recent past, is listed in leading international rankings as one of the world's very few non-English speaking media, and the now-standard translation and publication of all contributions in English will continue to improve the journal's position. (d) Do English-language publications lead to a change in the own research agenda? Of course this can happen in an enlarged competitive arena. The art of science consists in the successive development of stable long-term research results - successive means here that the sustainable results of a researcher form the basis for further research. This is usually done more quickly and systematically in the so-called main streams of scientific debate, which focus on more basic research questions of a subject, than by means of a more random bottomup emerging of such research structures in an ever-fragmenting world of knowledge. The internationally observable main streams just have more scientists in a field of research, who tend to relate more closely to each other and thus enhance the condition of successive research in comparison with national practices.

From a German-language perspective, the question is exciting of how we deal with a successful central-European field of research - I am talking about the design-oriented paradigm of BISE - which, in the eyes of the local protagonists, is given too little emphasis in the international context. Again in this case one can only reply that the international "market" follows its accepted laws, and if the German-language community does not sufficiently comply to these structures, the international as well as the national research suffers: The international research, since improved German-language results are recognized only with a certain delay, and the national because its quality is not sufficiently recognized in the international community. Thus, also here top international publications are required.

(e) What are the pitfalls of a non-native publication? The usual answer is probably that the authors need to deal with English words, sentence structure, precise expressions and language melody. Valid options for action are to read many excellent English-language articles and visit excellent international conferences in order to improve one's language skills, and to ask a native speaker to correct the paper just before the submission of a contribution (by the way: even prominent Englishlanguage authors use professional editing services before submitting their articles). I would like to allude to another hidden, but more serious issue. Especially in the top journals it can be frequently observed that the angle of view in the international field is larger, methodological rigor is more continuous, and thus also the construction of a scientific contribution differs from Germanlanguage articles - please bear in mind the above mentioned examples in (a) for the cultural context. An understanding of these differences can be achieved only to a limited extent through the standard methods and practices for studying a foreign language - here, the best option is to do research in the environment of an outstanding scientist in the international field for an extended period ideally in a joint project and several times in the course of research.

What kind of publication strategy should young academics then pursue in the light of these multi-dimensional challenges? Provided that the doctor father/mother is aware of the challenges are there any tools that help young people? Basically, today and in future the following applies: Those who aim at a future as a junior scientist in a research university must have English-language publications in top international journals (plural!).

At Frankfurt university, we have doctoral regulations allowing the cumulative dissertation, which thus aims at articles published in or submitted to top media (in the latter case, the first round of review should have been positive). Correspondingly, we set out a list of 20 international top mainstream media at our department based on the WKWI recommendation list, the Jourqual rankings of VHB, and less important international rankings (such as by Willcocks in EJIS 2008) - consisting of fifteen journals and five conferences (some exceptions may be made for other top media) - in the sense that only media are possible which are top in all of the rankings. The restriction to the mainstream increases the intensity of competition, but also increases the likelihood of acceptance of a very good contribution in a very good journal.

In a research department it is also important to ensure a substantial proportion of successive research given the high international quality standards - we should not assume that a rapid, in-depth 
exchange of knowledge objects, theoretical foundations, and knowledge acquisition procedures increases the individual publication opportunities.

We offer important parts of a structured doctoral program once a year with the help of top international researchers to the extent that significant theories and knowledge acquisition procedures are practiced; similarly, discourse events are held on fundamental contributions in top journals. On this basis, we use the above-mentioned five international reputable conferences with a doubleblind review process as a testing ground and therefore as a "step" for subsequent contributions to top international journals. In not more than 18 months after the start of a research study an accepted contribution should show the research quality of a young scientist. In the present environment, this specifically means: The journal WIRTSCHAFTSINFORMATIK is ranked as $\mathrm{B}+$ Journal (according to the Jourqual ranking) and thus is the fifteenth journal. Extraordinarily important obviously for the German-speaking countries, but also globally respected, the journal is an internationally reputable one - we had already set the target that contributions have to be published in several international journals. The other 14 journals consist of eight journals in the $\mathrm{A}+$ and $\mathrm{A}-$ field and six journals in the $\mathrm{B}+$ and $\mathrm{B}-$ range according to the international ranking. By the way: A task for authors of top publications is also (beyond the fact that they act as reviewers in international journals themselves) to "replay" their international experience in the development of the journal WIRTSCHAFTSINFORMATIK (and thus the local community) - for example (see (a)), to intensify the discourse with the contributing authors as a reviewer.

If this requirement is met, other targets come into view, such as knowledge transfer into the general community and into practice. This will also include the selective presentation of research results in important German-language media, such as in the biennial WI conference. We work empirically in many parts - and the documentation of collected data often takes the form of a book.

This structure has proven to be fundamentally sound to enable young scientists to meet the multidimensional challenges.

Prof. Dr. Wolfgang König

Chair of Economics, esp. Information Systems

University of Frankfurt, Germany

\section{Ritual or Benefit}

\subsection{Internationalization}

Closed markets are rarely efficient. Innovative excellence evolves in international competition, from telecommunications to the automotive industry to agriculture and arts. If we postulate efficiency as a value of economic activity, we must require international standards for science and particularly for Business and Information Systems Engineering (BISE).

\subsection{Situation}

At present, English is the lingua franca of science. Therefore, journals from the Anglo-Saxon, especially the American research community, i.e. IS research, have taken center stage in international scientific competition. The reviewers focus on the criteria for scholarly standard that are acknowledged in this community, resulting in a concentration of behavioral contributions with an easily verifiable methodical research approach.

Research policy and its excellence initiatives and the media with rankings, such as in the Handelsblatt, regard publications in the mentioned journals as being of international excellence. Universities have begun to align themselves with this view: They support anything that gains points and thus prestige. This applies to habilitation procedures, to the appointment of professors, and to the distribution of funds to departments. Young academics are increasingly becoming attuned to this approach since a few years.

Some BISE researchers see this simplistic assessment of science as a high risk, especially those from the German-language design-oriented BISE, but also by the representatives of the American Design Science:

- Behavioral studies are suitable for analyzing correlations, such as of price determination models and customer loyalty, but contribute little to the development of business models, such as the Apple Store or corresponding innovative transaction models. For the publication success, it is less risky to replicate an established research design than to formulate innovative solution approaches. However, if behaviorism does not support design science, innovation largely falls behind.

- The so-called top journals often put stronger emphasis on the research approach than on the results, as the space taken by the description of approach compared with the description of results shows. Scientific rigor often goes at the expense of utility, in designoriented as well as in behaviorist contributions. In order to justify a statement, it usually has to be considered so restrictedly that it is of very limited value for its application. The transfer of research results to economy and society is not taken into account.

- The question of the benefits for economy and society is hardly posed longer. Research seems to work for its own sake.

- Researchers spend more and more time traveling, as also giving talks contributes to the desired points and young researchers obviously attribute major influence to networking despite the double-blind reviews.

- The new criteria for scholarly standard threaten the cooperation between economy and science. This is less a question of language than of topics. Besides, every day that a researcher spends on the road or in committees is lost for the analysis of reality.

- Journal publications are only suitable for scientific results that can be described on a few pages (after deduction of the methodical reasoning). Reference models, such as for master data management, and methods, such as for the interaction within Internet shops, cannot be described in this context.

- Textbooks and similar book publications that summarize the current state in a field of knowledge are of fundamental importance for a scientific discipline; however, these are not considered in the one-dimensional perspective of science.

\subsection{Consequences}

Scientific research must be international and thus must be in English. On the one hand, it must be able to evaluate the available state of a research area and on the other hand has to make its results internationally accessible if high importance is attached to the dissemination of knowledge and approval within the discipline. Are the mentioned risks simply an unavoidable side effect?

Many universities have introduced the cumulative dissertation and promote it as it is attractive to the supervising professors as co-authors and to the faculty in 
order to gain publication points. In contrast, the book for the doctoral dissertation can be better planned than the somewhat random procedure of peer review of journal articles. From a scientific point of view, the book offers the opportunity to summarize the knowledge of an area, to develop comprehensive proposals, and to finally verify these to a greater extent than many journal articles. A relevant dissertation has also helped many doctoral candidates in their career.

At present, it is hardly possible to avoid the cumulative habilitation, even if in principle the same reservations apply. After having achieved the habilitation, young researchers will be judged in terms of their international publications when applying for a professorship, not in terms of their books.

Professors have the greatest freedom in choosing their form of publication if they do not desire calls to other universities, are not dependent on publication points in their faculty, and if their self-esteem is not determined by simplistic rankings. We must hope that enough of them continue to write good textbooks, guidelines for practice, but also principle works in form of books. They also have the obligation to publish design-oriented research internationally, and thus contribute to the acceptance of this approach and to the pluralism of methods respectively.

Important indicators are journals and scientific conferences. All scientists are responsible for the quality of the review process. The more a reviewer knows about the issue of a publication, the less he has to cling to the formalities of the research process and the more he is able to deal with the results.

It seems to be a matter of course that researchers analyze the publications within their own language area besides the English-language publications and publish in their native language if, e.g., this is necessary for teaching or the transfer into practice.

Internationalization and adequate performance measurement are not mutually exclusive, but should be combined. We must hope that the reductionist form of evaluating scholarly standards will take care of itself in the near future. The alienation of university from economy or administration could become one regulatory element, the quality and relevance of teaching another. Of course, a preventive correction of the mechanisms is preferable. Here, science could learn from practice: One-dimensional incentive systems have demonstrably led to disorder, which is why the annual objectives of executives and professionals are rarely limited to a single dimension.

Prof. Dr. Hubert Österle Institute of Information Systems University of St. Gallen, Switzerland

\section{What is the Correct Yardstick to Evaluate Research?}

The themes addressed in the interesting article by Urbach, Smolnik, and Riempp, and the subsequent comments offered by the colleagues Mertens and Schumann, and Urbach have prompted these brief reflections.

We are far from invoking one best way in research; nevertheless there are two indisputable facts:

1. research has a far higher significance than the university's other institutional activities;

2. research is increasingly evaluated according to international standards. The benchmark parameters must perforce be "global". On the other hand, in a society of dwindling mobility barriers between people, goods, ideas, and capital, it would be very strange if solely the fences separating the single national academic communities, or even specific disciplinary sectors, were to remain standing.

Why are international (English) publications important?

We must first make the distinction between language and content.

In terms of language, in the past a language dominated some specific fields, used by those who, for various reasons, wanted to diffuse their thinking and compare themselves with their peers: for centuries Latin was the language used to study medicine and law, while in its early years, German was the language of psychoanalysis, French and Latin were the languages of mathematics, while Italian was the language of classical music.

The scholar's goal is to push forward the frontiers of knowledge, but also to promote its diffusion. New knowledge can open new horizons of analysis and problem-solving. Therefore, someone focused on information systems research seeking an exchange of views with their peers has no option but to use English.

The reference community cannot therefore be delimited on the basis of national belonging but on practice, and needs a common language that, today, is unquestionably English, tomorrow perhaps not.

Content. Clearly, each country's scientific interests in the diverse information systems and related research topics can differ broadly in terms of approach and method, making it hard to compare and evaluate the results like in the experimental sciences.

Information systems - let's not forget - is a wide-ranging and multifaceted field of study, in which the core disciplines range from engineering to psychology. This obviously explains why the academics find it necessary to specialize in individual thematic areas. For example, in Italy, where the production landscape is populated by numerous small companies, the management of information, in line with a perspective that pivots around the mission of the smaller enterprises, is clearly dominant. In countries where finance is a significant driver, more than understandably the interest lies in themes related to the role of ICT in trading operations or competitive strategies. In nations featuring a developed and ubiquitous technology infrastructure, the focus is on the effects of the ICT applications on the citizen and society as a whole.

Generally, the conditions in which to direct, develop, and enhance the value of research and its results are created in places that can draw on clusters of specific skills and an array of analytical and qualitatively satisfying data issued by the public authorities and specialist bodies.

For example, in those countries where a person's medical record can be used as court evidence, the physicians are induced to provide a complete and accurate picture of the facts. Unlike colleagues in other countries, academics in countries that make these huge database contents available for research have the advantage of access to the high quality empirical data contained therein.

Italy's central bank (Banca d'Italia) has been methodically and rigorously gathering a whole series of detailed information (accounting, financial, organizational, and technical) from each financial intermediary (such as banks, insurers, investment companies). This information capital has enabled many of our colleagues to improve their academic position and to build research structures empowered to give a valuable contribution to both the scientific and professional communities. 
Meanwhile, the report on the public agencies issued by the US General Accounting Office (GAO) is a source of information that has been drawn on by generations of scholars. But there are many other examples, too.

Are books, collected editions, or monographic dissertations less valuable than peer-reviewed articles?

Articles in the English language in international journals are a "ticket" to enter a vast and recognized community. In an academic career, that "admission ticket" is a payment "in installments", a rule that not even the most authoritative researchers can circumvent.

I'd like to emphasize that the evolution underway must not lead the publishers to abandon the publication of books, research monographs, and articles in quality national journals. Quite the contrary: in fact, each community should encourage young researchers to present the results of their studies in a balanced way, by which I mean using both the prestigious international journals and the more traditional outlets.

The impact and significance of monographs is different to peer-reviewed articles, of which the latter are put through a tough selection process, while books are generally subject to a less strenuous review process. However, books organize, make in-depth investigations and systemize knowledge on a specific theme. In their highest expression they are indicative of the scientific maturity of the respective authors. As a result, it would be a mistake to dismiss the value of books and collected editions.

In Italy, the debate on the need to publish in the international journals, and also on the possibility of replacing the monographs with papers, is in full flow. There is much reflection also on the pros and cons of cumulative dissertations. The publication of work in "impact factor" journals by disciplines such as biology, pharmacology, chemistry, engineering, physics, and natural sciences in general has been long considered a key part of the assessment of young scholars and of the departments' scientific productivity.

For some years, Information Systems classed as a social science and, in Italy, under the umbrella of business studies - has been lobbying for uniformity with the international community. An alignment process was also suggested by the parallel legislative and institutional reform of the Italian university system, which has led to the setting up of special bodies to monitor and report on scientific output and which, before, were practically nonexistent. The favorable stance on "impact factor" publications has taken root and, consequently, so has the recognition of the value of cumulative dissertations and peer-reviewed articles versus the traditional monograph. Nevertheless, this process has only just begun and concrete evidence of its definitive adoption will not ensue until the examining boards called to comparatively assess the candidates have shown they can operate in line with the new criteria.

Italy is clearly charting a course towards the internationalization of research, although the timing and ways of the transition from a "book generation" to a "peer-reviewed paper generation" of academics are far less clear.

What does society expect from our work?

Visibility, prestige and international reputation are only a part of the mission of a scientific community. In fact, the other part of the mission includes:

(a) develop and diffuse knowledge useful to its country or to specific economic sectors. In Italy, that means, for example, focusing on topics that might be of limited interest to the readers of the top international journals, but crucial to improving the national culture;

(b) implement a quality system of instruction that doesn't necessarily reconnect to knowledge developed with the use of sophisticated tools and methods, as, on the other hand, required by the international scientific community.

In short, international prestige should not be pursued at the cost of losing one's own identity. If we want to make our small contribution to the world then there is no other way than to make our voices heard. This can be done in any language as long as it reaches the right audience.

What are the pros and cons of today's international English in language and AngloSaxon in approach publication criteria?

As we have seen above, the growing importance of international (English) publications is essentially due to two factors:

1. the scholarly community needs to easily share and exchange ideas and outcomes on a global scale;

2. scholars of all countries tend to be increasingly evaluated on the basis of the number and authoritativeness of their international publications.
These two factors are very different in nature. In the first case, international (English) publications are encouraged for the general interest of knowledge development, whereas point two identifies the desire of single researchers to make a career as a basic trigger for the growing importance of international publications.

These two factors tend to interact in a strong spiral of mutual positive feedbacks, which results, for historical reasons, in a global spreading and strengthening not only of English as a common language, but also of Anglo-Saxonoriented standards for the evaluation of scientific writings and research outcomes.

This situation can be usefully enlightened with the tools of ecology of knowledge. In terms of eco-evolution, factor one (knowledge sharing) is of course very important, but the ensuing factor two (a rewards system to encourage knowledge sharing) is a double-bladed weapon.

Let's make an example, drawn from evolutionary studies. Each organism can be considered as a knowledge system, where knowledge can be stored in the DNA, in the immune system, in the brain, etc. It has been shown that, if we take an organism as a knowledge system, rewards will tend to make it more efficient and more stupid.

For example, a peacock who is rewarded by a female (a peahen) for its magnificent tail will tend to reproduce peacocks with increasingly sumptuous tails, until this becomes counterproductive to its survival.

Likewise, a human being who earns a reward by solving problems in a specific way (for example, by complying with office practices... or with international review processes) will end up becoming blind to any form of alternative solution, even if these are glaringly obvious and also much better. In other words, we specialize too much in earning the reward in itself, until it eventually becomes a straitjacket.

As a result, any kind of knowledge system (whether peacocks' DNA or academic community) subject to a rigidly enforced system of punishments/rewards is bound to lose elasticity and gain in stupidity until it crosses the critical threshold: the peacock with his excessive tail would no longer be able to live in nature.

Well, peacocks are lucky: as long as they are considered beautiful someone will feed them, and they will survive in the comfortable protected environment 
of zoos. But maybe the scholarly community should go beyond the hope of being fed for their self-referential skills. In other words, international standards of evaluation for scientific writings are essential to allow knowledge sharing, but, in an eco-evolutionary perspective, these standards should maintain a certain degree of pluralism; more specifically, a single, specific, rigid evaluation system should not become the only one through which a career in the academic world is possible.

Within punishment/rewards systems, in fact, something similar to Gödel's incompleteness theorems goes into action: the more a (reward) system is powerful, the more it is incomplete with respect to reality. Thus, the more a scholarly community tends to rely on a single, rigid reward system, the more it is bound to lose contact with the real world, and to go towards peacocks' destiny (either zoos, or extinction... depending on feeders' will).

So, in my opinion, if we put things in perspective, we cannot deny that the maintaining of a set of different reward systems (the international Anglo-Saxon and national systems rooted in local, specific socio-economic needs, for instance) would create a range of "alternative rewards" to ensure the "biological diversity" of that strange species known as researchers. . . the essential - albeit insufficient - condition for thwarting the onset of stupidity in our troops.

It is the job of our colleagues in the scientific community to discover new and different strands. Meanwhile, BISE has the job of not losing the plot.

Prof. Dr. Marco De Marco Facoltà di Economia Università cattolica del Sacro Cuore Milano, Italy

\section{BISE-Related Research in Spain: A Personal View}

After having read with pleasure about the long history of the various German computing journals ending up in WIRTSCHAFTSINFORMATIK, which have surely contributed to the growth and cohesion of the German community of researchers and professionals in BISE, I must admit that no similar story can be told about Spain. As I see it, we in Spain have had and still have most of the components for writing a similar script: many research groups working in areas close to BISE, computing careers being offered at most universities, a $40+$ year old journal, several internationally highly-ranked business schools, a recent scientific society, etc. However, I would say that, unfortunately, we have lacked the willingness and the contextual conditions to build a community similar to the German BISE one. Certainly, there is no Spanish research community working in BISE as such, at least none with the goals, meaning, and current research lines indicated in the first issue of your BISE journal (Buhl 2009).

For more than a decade, Spanish researchers from most BISE-related groups have gathered at the national meetings named JISBD (Spanish Meeting for Software Engineering and Databases), run in Spanish. Some of these have explicitly called for papers on IS issues. Most notably, along this widening line towards BISE, I would like to mention the repeated organization of two workshops, respectively named PNIS (Business Processes and Services Engineering) and MIFISIS (Research Methods and Fundamentals for Software and Information Systems Research). So far, however, the subjects of these workshops still remain outliers with regard to the main published topics of the meetings.

Overall, the community of researchers usually attending JISBD represents research groups that are successful in international publishing records and relationships. They increasingly publish for top conferences and in international journals of their respective specialist field. Senior researchers from those groups are well known internationally and take part in program committees and editorial boards. Resulting from these longestablished relationships, most of the relevant top conferences in those areas have been organized in Spain in the last decades, such as ER, RE, ESEC, CAiSE, or VLDB, organized in Barcelona, or EDBT and DEXA in other Spanish cities.

With regard to the Business and applied IS sides of BISE, in Spain there are a few small research groups, working at the three best-known business schools of the country (IESE, ESADE and IE) and at a few universities, such as Universidad de Castilla-La Mancha, Universidad de Alicante, and the Open University of Catalonia, among other emerging initiatives. Being newer and smaller in staff numbers than their SE and IE counterparts, the activity of these groups has also had a valuable international projection, with their members publishing in most main IS conferences and some IS journals. They have also organized some of those events, such as ICIS and ECIS in Barcelona, or ICEIS, EMCIS, and ECRM in other Spanish cities.

Thus, we could say that the overall contribution of Spanish research somehow related to BISE recently is competitive in terms of international quantitative standards, with the highest number of researchers working on Software Engineering and Information Engineering, some groups on Information Systems Engineering, and a few scientists dedicated to Business Information Systems or Business Systems Engineering. This situation is similar to many other research areas in Spain. It has been noted and published by government officials and research institutions that Spain is, in many areas, not anymore behind similar countries in terms of publishing quantitative contributions. However, the same officials and institutions, together with the industry, increasingly complain about the large gap, if not abysm, between such a big research effort and investment in universities and research centers on the one side, and on the other side the almost non-existent return on that investment in terms of new Spanish patents, products, services, entrepreneurships or spin-off companies, directly or indirectly arising from that research. This is now, also for BISE-related research, one of the largest issues in Spain, both at the level of the official discourse in favor of more innovation (' $\mathrm{I}$ '), from the $\mathrm{R}+\mathrm{D}+\mathrm{I}$ equation, and at the level of the newer terms and conditions established in public calls for funding research projects in universities and/or companies.

This connects with the issue of research approaches and methodologies typically followed in the BISE-related Spanish research. I can state without much risk for error that most of the research done by our local community is indeed engineering research, and follows implicitly the tenants of Design Research, but paradoxically without much apparent knowledge of Design Science. It is very rare to find any section or paragraph presenting or justifying the research method or approach followed in papers or $\mathrm{PhD}$ dissertations in our local community. From the outline of the document it can usually be concluded that the research work corresponds to a variant of Design or Engineering Research, but this is implicit and sometimes implies 
weaknesses in one or several of its research cycles: relevance, design and rigor. If I had to order those three cycles for Spanish BISE-related research according to the efforts and strengths shown in published documents, this would be my guess: 1st design; 2nd rigor; 3rd relevance. More recently, some groups are trying to push for more empirical research, for example in software engineering. However, I would say that so far their understanding of 'empirical' is more along the line of quantitative behavioral research of the software system than towards more socio-technical behavioral studies. Qualitative research studies in BISE are still the exception in Spain, with some of them showing explicitly their use of qualitative research methods and techniques such as in-depth case studies, action research, participant observation or Grounded Theory studies, always inspired by and applied to real industrial or public administration cases and professional issues.

We could regard the situation in Spain as if we had already solved the issue of international publishing in quantity, and theoretical quality, but still lag long behind other more competitive economies in terms of practical and methodological quality of our research efforts. In my opinion this is also the case for BISE-related research. Of course there are many reasons for such a state of affairs, from socio-cultural through historical to economic and institutional ones. But it is common to hear, when these issues are discussed publicly and privately, that Spain should aspire to be like Germany or the USA, as if these two countries were alike in research cultures.

Certainly, both Germany and the USA, but not only these countries, share some characteristics that are usually missing in Spain. With a few notable exceptions, much of the Spanish BISE-related university research is done quite disconnected from local companies or professionals. Looking at it the other way, not many companies in Spain invest in $\mathrm{R}+\mathrm{D}$ related to BISE, while I would say that a lot of them try to innovate by using international services and products related to BISE, such as ERP, CRM, or SCM systems and services. In my eyes the main problem lies in the difficulties and the lack of incentives for sharing and communicating between innovative companies and university research groups. With some valuable exceptions, up to now Spanish university researchers in BISE-related themes have not found much need to work in a continuous way with local companies or institutions which have practical BISE problems. Reversely, only a few companies or public administrations consider doctoral students or PhD graduates as a source of potential innovation for their practical affairs in BISE.

The situation in Spain is in clear contrast to what is happening in countries like Germany or the USA for the BISE discipline and their diversity of programs, with some more technological, others more theoretical, others more applied and some hybrid. Most doctorate programs in Spain have concentrated in techno-theoretically oriented issues, usually covering mostly the specialist areas of the local PhD supervisors, and with practically no course on research methods. In fact, for many years, while Computing Schools were growing all over Spain, doctorate programs basically educated the younger teachers needed by those schools in research, rather than in development and innovation. This situation has not much helped in closing the communication gap with local companies, which often regard $\mathrm{PhD}$ graduates as unpractical and suspicious professionals. In contrast with the new official discourse in favor of more practical and useful research, still public criteria for accreditation and promotion of university professors in engineering and computing clearly favors international publishing in quantity and theoretical quality, rather than local or applied research. This reinforces the local weaknesses in industry-university communication and more relevant research, which will probably be exacerbated by the recent pressure to publish mainly in indexed journals.

With regard to publication practices among the described community of BISE-related researchers, it can be inferred that most of them have made their best efforts to publish internationally, basically in English-language conferences and journals. The JISBD meeting, with its related workshops and events, is the sole event where that community has published in Spanish, and in many occasions by sending ongoing or initial research papers that were later improved and sent in English to international events. Although in Spain there is no WIRTSCHAFTSINFORMATIK journal as such, with a clear BISE orientation both for researchers and professionals, we do have a $40+$ year old journal named Novatica, edited by ATI, the oldest association of IT professionals in Spain. With a similar history as its German counterpart, Novatica has remained more as a professional forum than as a research journal, even though it has always welcomed research papers throughout its history, with some of the its first editors and authors becoming the first full university professors in several computing areas. Novatica does not have a specific focus on computing, thus covering all computing specialities, but given its professional orientation, it is also the place to publish BISE research in Spanish. Both at JISBD and Novatica there have been public complaints and discussions with some senior professors stating that Spanish BISE-related researchers were more aware of international research than of what their local colleagues were doing. There was even a citation study presented at JISBD showing how little Spanish research was cited in papers published by the local research community.

The situation that I have described above presents my opinion of the state of affairs concerning BISE-related research in Spain. It is, thus, my personal view, although I would surely find many colleagues in Spain who share great parts of this statement. Most of us look at countries like Germany or the USA for better research practices, and admit to - in a healthy way - envy the working conditions and contextual situation of our colleagues there. We have much to learn from your situation in Germany in building a more cohesive and focused research community, committed to and interleaved with the interests of professionals, companies and public administration, with a long history and strong expertise of using Engineering Research for building sound solutions to practical problems, and where doctorates and $\mathrm{PhD}$ graduates are considered at a very high level, socially and professionally. I wish you can maintain and improve that situation, built upon local experience, rather than to delude it into more global research practices.

In my opinion, a key to a more successful future for research in BISE, in Germany, Spain and elsewhere, lies in its effective "glocalization", where our research is increasingly based on local practical issues and problems, worked and shared in cooperation and coordination with other local colleagues through journals such as WIRTSCHAFTSINFORMATIK and Novatica, in languages such as German, Spanish, or English, but also with a global stand and ambition 
that enforces our theoretical and practical contributions in fair "coopetition" with colleagues from elsewhere, and most specially from Europe. If I could now have a dream, it would be one of making WIRTSCHAFTSINFORMATIK and other similar European journals in BISE, such as the Scandinavian Journal of IS, share efforts to cover and present a European view of the BISE discipline. There Novatica could play a role of reaching in Spanish the growing number of BISE researchers and professionals in Latin America and the Spanish-speaking USA. Yes we could.

Prof. Joan A. Pastor

UOC - Open University of Catalonia \& UPC, Barcelona, Spain

\section{The Iron Law of National Rankings}

"Can national research, issued in national non-English publications be considered in international publications?"

Even from a French viewpoint, there is no question that the main international language for scientific publications is the English language. In Information Systems, international recognition, i.e. beyond a language zone, requires to publish in English, possibly in the best English/American outlets. For the IS disciplines the AIS provides a basket of six journals that are considered among the very best: MIS Quarterly, Information Systems Research, European Journal of Information Systems, Information Systems Journal, Journal of the Association of Information Systems and Journal of MIS. In terms of impact factor, along with three journals in psychology, MIS Quarterly is really dominating the field as well as the social sciences.

This being said, the real issue is the effort one wants to invest to publish at a very high level. From the viewpoint of a young non-native English speaking European scholar the cost of trying to publish in the very best American journals is huge. For a French - and I'd be tempted to generalize to all European Latin countries - even if one starts with a very good piece of research first written in French and possibly published in Systemes d'Information et Management', the leading journal of the French-speaking community, this probably takes at least four major adaptations. First the references would not be exactly the same as it is clear that the potential reviewers would appreciate to be cited even if the use of such references is very minor. Second, the paper structure is very different. In French an elegant demonstration does not start as in many American journals with the major findings or proposals. Those have to be progressively unveiled. Third, the results are not always universal. As a consequence arguments themselves often have to be adapted according to the context. This can be related to the methodology. It is well known that describing the context of a study and the operational details is more highly valued in France or Germany than in the US. For many of us, in-depth contextualization can be considered to illuminate and alter considerably the results of the research. Also using discrete variables rather than continuous variables is generally considered more relevant in France than in the US. Fourth, the reviewing process will be conducted differently and the freedom of the authors can be considered to be much greater in Europe than in the very top US journals. "What gets published? The combined views of authors and reviewers in a paper which has had any content that is not rigorously supportable removed from it. So it is not uncommon for the final published version of the paper to be rather bland, self- evident and endlessly citable, since it is hardly likely to contradict the paper in which it is cited." (Paul 2008, p. 328).

Given these difficulties, there is a clear advantage to publish in national nonEnglish publications, especially when doing one's first steps in a career. In addition, when the national top journal has high recognition manifested by its national ranking in the list of journals, as is the case with Systemes d'Information et Management and WIRTSCHAFTSINFORMATIK, it is less risky, especially if the paper is characterized by being very representative of the countryspecific culture, and still considered excellent for one's record. Overall, what prevails are the publications that meet the criteria of the most powerful incentive system which is, for the majority of colleagues, highly correlated to the national ranking list when there is one. This may have some drawbacks (see Marco de Marco's viewpoint). Paul is adding a more nuanced and critical view: "journal league tables are to do with promotion procedures and rites of passage in academia, not quality research." (Paul
2008, p. 329). Altogether, for more mature or self-confident, non-native English speakers, I advocate a mixed strategy. It consists of publishing more classical research and/or less advanced projects in the national journal and from time to time sending a probe or what one thinks absolutely deserves a worldwide audience to the journals who have such audience. If one wants to get one's research with an authentic European flavor, and not a melting pot, published, it does not necessarily mean the highest rank! One question often raised in France is to know whether it is acceptable to translate one's best article and send it to the top worldwide journal. My answer is the following. Either the translation is really close and, apart from dissemination which is a great benefit, at the National Level (Conseil National des Universites, cf. Rowe 2006) this has little impact. Or, if not rejected, it may end up being lost in translation, so that the author does not recognize it anymore! To favor the first outcome, one strategy is to co-author with an American colleague from the beginning of the project knowing that you are going to send it to a journal whose reviewing process follows a different culture. Another strategy is to find a top international journal with a European culture, which to me means respectful of author's identity, in terms of culture. Respecting this publishing culture does not mean not asking authors to be focused on a clear set of related research questions when presenting their ideas, or encouraging a poetic style, but it should respect different types of contributions, some emphasizing practical aspects, and not oppose the broad literature and/or philosophy to normal science as it is sometimes implied (Lyytinnen et al. 2007).

Prof. Dr. Frantz Rowe Institut d'Economie et de Management de Nantes - IAE, France

\section{References}

\section{to: Introduction}

Buhl H (2009) 50 years of WIRTSCHAFTSINFORMATIK: Moving on to new shores. Business \& Information Systems Engineering 1(1):1-4

Buhl $H$, Mertens $P$, Schumann $M$, Urbach $N$, Smolnik S, Riempp G (2010) Business \& Information Systems Engineering 2(2):109-114. http://www.bise-journal.org/ pdf/6_02696.pdf 
Österle H, Winter R, Brenner W (eds) (2010) Gestaltungsorientierte Wirtschaftsinformatik: Ein Plädoyer für Rigor und Relevanz. St. Gallen

\section{to: BISE-Related Research in Spain}

Buhl H (2009) 50 years of WIRTSCHAFTSINFORMATIK: Moving on to new shores. Busi- ness \& Information Systems Engineering $1(1): 1-4$

\section{to: The Iron Law of National Rankings}

Lyytinnen K, Baskerville R, livari J, Teeni D (2007) Why the old world cannot publish? Overcoming challenges in publishing highimpact IS research. European Journal of Information Systems 16:316-326
Paul R (2008) Measuring research quality: the United Kingdom government's research assessment exercise. European Journal of Information Systems 17:324-329

Rowe F (2006) The editorial view of Frantz Rowe Editor in Chief: of Systemes d'Information et Management Third in a series - On dissemination, national language and interacting with practitioners. European Journal of Information Systems $15: 244-248$ 